\title{
The electrolysis of ammonium dinitramide in dimethyl sulfoxide
}

\author{
Yu-ichiro Izato, ${ }^{*[a]}$ Kazuki Matsushita, ${ }^{[a]}$ Kento Shiota, ${ }^{[b]}$ and Atsumi Miyake ${ }^{[b]}$
}

\begin{abstract}
This work investigated the electrolysis of ammonium dinitramide $\left(\mathrm{ADN}\right.$ : $\left.\mathrm{NH}_{4} \mathrm{~N}\left(\mathrm{NO}_{2}\right)_{2}\right)$ in dimethyl sulfoxide (DMSO). Various fundamental electrolysis properties of ADN were assessed based on an electrochemical study and the associated mechanisms were examined based on a quantum chemical approach. ADN exhibited three redox peaks at $-0.69,-1.16$ and $-1.52 \mathrm{~V}$ and two oxidation peaks at 0.34 and $0.50 \mathrm{~V}(\mathrm{vs} \mathrm{Ag} / \mathrm{AgCl})$ at a scan rate of $50 \mathrm{mV} \mathrm{s}^{-1}$ during cyclic voltammetry trials with a platinum electrode. Ultraviolet-visible spectra of ADN in DMSO were also acquired to determine temporal changes under galvanostatic reduction conditions. These spectra showed that a continuous current in conjunction with an applied voltage of $-1.5 \mathrm{~V}$ decomposed the ADN, but were unable to elucidate electrolysis products. Quantum chemistry calculations identified possible pathways for the electrolysis of ADN in DMSO, and indicated that reduced ADN rapidly decomposes to form $\mathrm{NH}_{3}, \mathrm{~N}_{2} \mathrm{O}, \mathrm{NO}_{2}$ and $\mathrm{OH}^{-}$. The associated Gibbs energy barrier was determined to be almost $0 \mathrm{~kJ}^{\text {mol}}{ }^{-1}$ when calculated at the $\mathrm{CBS}-\mathrm{QB} 3 / / \omega \mathrm{B} 97 \mathrm{X}-\mathrm{D} / 6-311++\mathrm{G}(\mathrm{d}, \mathrm{p}) / \mathrm{SCRF}=(\mathrm{smd}$, solvent $=\mathrm{dmso})$ level of theory. These results suggest that $A D N$ can undergo electrolysis in a solvent for which the potential window is sufficiently wide given the application of the appropriate voltage.
\end{abstract}

Keywords: Ammonium dinitramide, Electrolysis, Cyclic voltammetry, UV-Vis spectrometry, Reaction pathway

\section{Introduction}

Liquid hydrazine and its derivatives (such as monomethyl hydrazine and unsymmetrical dimethylhydrazine) have been the most widely used spacecraft monopropellant and hypergolic bipropellant systems, respectively, since the 1950s. These propellants exhibit excellent performance and continue to be regarded as the state-of-the-art, but they also have several drawbacks that increase handling and storage costs. These include high crystallization points, significant toxicities, high vapor pressures at room temperature and detonation sensitivity to adiabatic compression. Thus, one of the goals of modern explosives chemistry is to replace such propellants with so-called "green" substances that avoid some or all of these challenges.

Energetic ionic liquid propellants (EILPs) are among the most attractive candidates for nextgeneration, so-called green, high-performance monoand bipropellants, due to their low vapor pressures (meaning a reduced risk of exposure to toxic vapors) and high energy densities [1-4]. In addition, EILPs can be fine-tuned to adjust their energy content, performance and physical properties by using various combinations of suitable anions and cations. The discovery of IL hypergols [5], which ignite instantly upon contact with an appropriate oxidizer, has also opened up a new research avenue related to bipropellant applications. Thus, the exploration of highperformance hypergolic EILPs has become of interest in the field of IL chemistry, and there have been numerous studies related to new hypergolic EILPs [59] and their hypergolic mechanisms [10-14].

In contrast to the vigorous development of EILP bipropellants, the study of ElLP-based monopropellants (that is, self-oxidizing systems) has been very limited to date. This is primarily because a monopropellant must have both an appropriate oxygen balance and suitable combustion characteristics, which greatly increases the difficulty in designing such compounds [3]. In addition, it can be difficult to ignite ILs due to their extremely low vapor pressures and high thermal stabilities. This has limited the applications of EILPs as monopropellants, since these liquid propellants must decompose and combust in the absence of an external oxygen source. It should also be noted that EILP-based monopropellants intended for the propulsion of spacecraft must ignite in response to very minimal energy inputs. Even so, the extremely low vapor pressures and superior thermal stabilities of EILPs are also beneficial, because these properties reduce evaporation/sublimation and so limit the exposure of personnel to potential hazards during storage and handling of the propellants. Thus, the development of EILP-based monopropellants will require the negative aspects of EILPs to be mitigated without losing the beneficial properties.

The ignition and pyrolysis of EILPs are challenging and so present-day combustor designs involving catalytic heaters are not suitable for the ignition of these substances. There are significant challenges and inefficiencies associated with current systems, and innovative approaches are therefore required to develop alternative combustion technologies in conjunction with the exploration of novel propellants. The ignition of EILPs via electrolysis is one possible solution. However, electrolysis reactions differ significantly from pyrolysis processes. Specifically, electrolysis involves chemical changes induced by passing an electric current through a conductive solution or a molten salt (including ILs), while pyrolysis is the decomposition of a material due 
to heat in the absence of oxygen or other reagents. Thus, electrolysis can be expected to promptly decompose even thermally stable EILPs.

Propellants based on ammonium dinitramide (ADN) and hydroxylammonium nitrate (HAN) have been widely studied as alternatives to hydrazine-based propellants. ADN has attracted attention as a potential liquid monopropellant because it has both a high oxygen balance and a significant energy content but does not contain halogens [15-17]. As an example, the novel ADN-based liquid monopropellants LMP-103S and FLP-106, consisting of blends of ADN, water, methanol and ammonia, were previously developed within a co-operative project between the Swedish Space Corporation and the Swedish Defense Research Agency [15, 18]. In addition, SHP163 [19-23] and AF-M315E [24] are promising HAN-based propellants. It should be noted that, in the field of chemical propulsion, a propellant made of an energetic salt dissolved in a solvent is considered to comprise an IL, and so these HAN propellants are referred to as ILs even though traditionally an IL is defined as consisting of only a single ionic compound.

A previous study by our group [25] established that a binary mixture of ADN and monomethylamine nitrate (MMAN) produced a deep eutectic IL at room temperature. The resulting mixture had a melting point of $3{ }^{\circ} \mathrm{C}$ (far less than the melting points of pure ADN and MMAN: 93 and $109{ }^{\circ} \mathrm{C}$ ) but was still difficult to ignite as a result of its high thermal stability [26].

Our long-term goal is to develop an ADNbased monopropellant in conjunction with an innovative combustor incorporating an electrolytic ignition system. To assess the feasibility of employing this type of ignition system with ADN-based monopropellants, we assessed various fundamental electrolysis characteristics of ADN based on an electrochemical approach and investigated the associated mechanisms based on a quantum chemical approach. The electrochemistry of aqueous ADN solutions [27] has previously been reported and the potential window of $\pm 1 \mathrm{~V}$ (vs a normal hydrogen electrode) is too narrow to allow a suitable assessment. Therefore, in the present work, electrochemical data for ADN were acquired in the non-aqueous solvent dimethylsulfoxide (DMSO), using cyclic voltammetry (CV) and ultraviolet-visible (UV-vis) spectroelectrochemical studies. Potential electrolysis pathways were also identified using quantum chemistry calculations.

\section{Experimental and Computational Section}

\subsection{Materials}

The ADN used in this work was obtained from the Hosoya Pyro-Engineering Co., Ltd., Japan, while the DMSO was sourced from FUJIFILM Wako Pure Chemical Industries, Ltd., Japan.

\subsection{Cyclic voltammetry}

ADN solutions were prepared by dissolving solid ADN in pure DMSO at a concentration of $2 \mathrm{mM}$, after which CV data were acquired using a Model 1200C electrochemical analyzer (ALS Co. Ltd., Tokyo, Japan) with a three-electrode cell having a working volume of $20 \mathrm{~mL}$. The working electrode was a platinum electrode $(\phi 6 \mathrm{~mm})$ with a $\mathrm{Ag} / \mathrm{AgCl}$ reference electrode (ALS Co. Ltd., Tokyo, Japan) and a platinum counter electrode ( $\phi 6 \mathrm{~mm}$, height: $57 \mathrm{~mm}$ ). All the potentials reported herein are relative to a $\mathrm{Ag} / \mathrm{AgCl}$ electrode. $\mathrm{A}$ linear potential sweep $(-2.5-1.5 \mathrm{~V})$ was applied to the working electrode through a potentiostat and the current at the electrode/electrolyte interface was recorded. The effect of the scan rate on the peak current density was determined by recording cyclic voltammograms at rates from 50 to $300 \mathrm{mV} \mathrm{s}^{-1}$. Each solution was purged with nitrogen gas before applying a potential and all analyses were performed at room temperature $\left(21^{\circ} \mathrm{C}\right)$.

\subsection{UV-vis spectroelectrochemical study}

The experimental set-up for the UV-vis analyses is shown in Figure 1. In each trial, a $2 \mathrm{mM}$ solution of ADN in DMSO was used and amperometry was also performed, employing a Model 1200C electrochemical analyzer (ALS Co. Ltd., Tokyo, Japan). UV-vis spectroelectrochemistry was carried out with an SEC2020 spectrometer (ALS Co. Ltd., Tokyo, Japan) in combination with a reflection probe, applying a nearnormal reflection configuration in a reflection cell (ALS Co. Ltd., Tokyo, Japan). UV-vis spectra were acquired using a Varian Cary 5 double beam spectrophotometer, with scans at $1 \mathrm{~s}$ intervals over the wavelength range between 200 and $600 \mathrm{~nm}$.

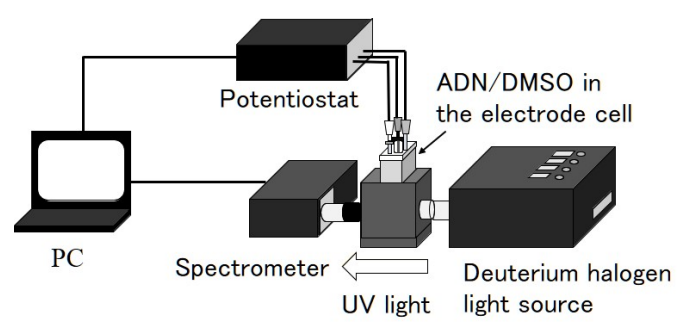

Figure 1. The experimental set-up employed during the UV-vis spectroelectrochemical experiments.

\subsection{Quantum chemistry calculations}

Potential electrolysis mechanisms were investigated using quantum chemistry calculations. The geometries of the reactants, products and transition states (TSs) were identified and optimized at the $\omega \mathrm{B} 97 \mathrm{X}-\mathrm{D} / 6-$ $311++G(d, p)$ level of theory, using the Gaussian 16 program package [28]. The $\omega \mathrm{B} 97 \mathrm{X}-\mathrm{D}$ method was previously developed by Gordon et al. [29] and includes empirical dispersion forces that are believed to play an important role in the reactions of polar species in liquid media. During these computations, TSs were extensively searched for and, if found, an intrinsic reaction coordinate calculation was conducted 
to confirm reactants and products related to that TS. The energies of the corresponding molecules were evaluated at the CBS-QB3 [30] level of theory. Details regarding the CBS-QB3// $\omega$ B97X-D method and the performance of this approach can be found in the work of Matsugi and Shiina [31]. Geometries and frequencies were calculated at the $\omega \mathrm{B} 97 \mathrm{X}-\mathrm{D} / 6-$ $311++G(d, p)$ level with zero-point energy (ZPE) correlation and frequency scaling factors of 0.975 and 0.950 , determined using the method of Alecu et al [32], the optimized geometries were fixed with no changes allowed, and the energies were calculated using the CBS-QB3 method. The CBS-QB3 energy values were subsequently corrected with ZPE and thermal corrections based on the $\omega$ B97X-D. Solvent effects were included by applying the self-consistent reaction field (SCRF) and solvation model based on density (SMD) options [33] within the program when investigating the liquid reactions. The SMD model is known to generate solvation energies that are typically accurate within $1 \mathrm{kcal} \mathrm{mol}^{-1}$ in the case of neutral molecules [33]. A scaling factor of 1.2 was used for cavity size in this study (as opposed to the Gaussian 16 default value of 1.1).

\section{Results and Discussion}

\subsection{Cyclic voltammetry}

Figure 2 presents the cyclic voltammograms obtained from ADN/DMSO solutions at various scan rates. Three redox peaks are observed, at $-0.69\left(E_{\mathrm{p} 1}{ }^{\mathrm{c}}\right),-1.16$ $\left(E_{\mathrm{p} 2}{ }^{\mathrm{c}}\right)$ and $-1.52 \mathrm{~V}\left(E_{\mathrm{p} 3}{ }^{\mathrm{c}}\right)$, while oxidation peaks are observed at $0.34\left(E_{\mathrm{p} 1}{ }^{\mathrm{a}}\right)$ and $0.50 \mathrm{~V}\left(E_{\mathrm{p} 2^{\mathrm{a}}}\right)$ at a scan rate of $50 \mathrm{mV} \mathrm{s}^{-1}$. With increases in the scan rate, all the redox peaks shifted to lower voltages, and $E_{\mathrm{p} 3}{ }^{\mathrm{c}}$ was found to correlate with the square root of the scan rate (Figure 3). The average ratio of the reduction current $\left(I_{\mathrm{p} 3} \mathrm{c}\right)$ to the corresponding oxidation current $\left(I_{\mathrm{p} 1} \mathrm{a}\right)$ was approximately 0.4 (that is, $I_{\mathrm{p} 1} \mathrm{a} / /_{\mathrm{p}}{ }^{\mathrm{c}}$ was less than 1 ). These results suggest that the electrochemical reaction was irreversible, meaning that the reaction rate at the electrode was slower than the diffusion process.

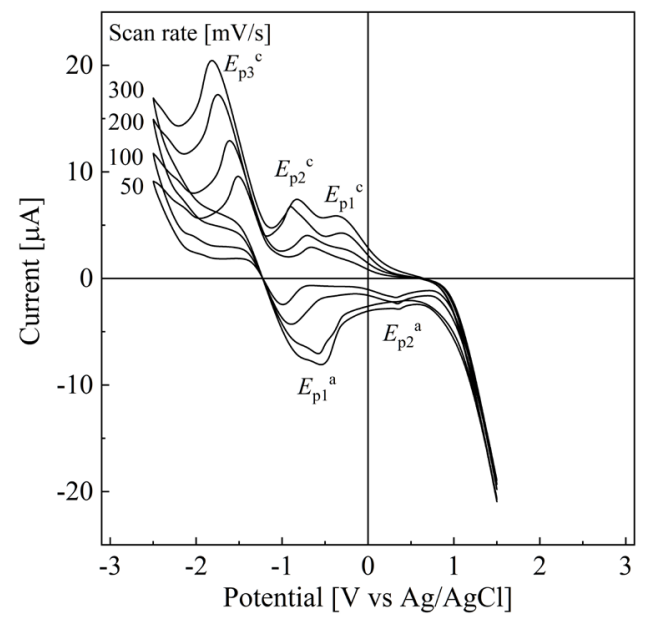

Figure 2. Cyclic voltammograms obtained from $A D N$ in DMSO (2 $\mathrm{mM})$ at various scan rates.

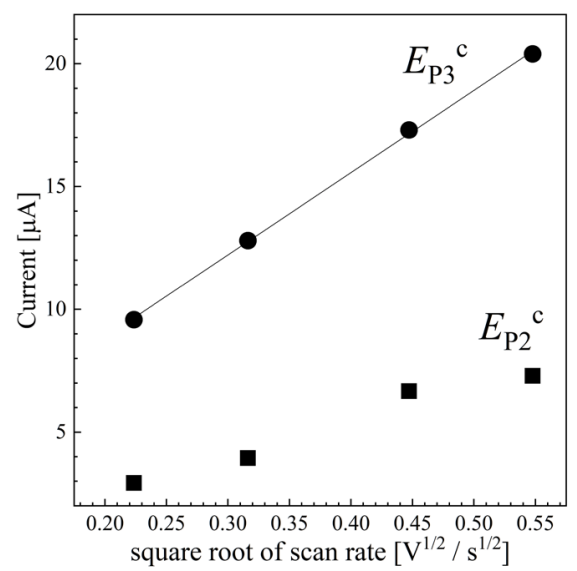

Figure 3. The reduction current at $E_{\mathrm{p} 2}{ }^{\mathrm{c}}$ and $E_{\mathrm{p} 3} \mathrm{c}$ as a function of the square root of the scan rate.

\subsection{UV-vis spectroelectrochemical study}

The UV spectrum of ADN is characterized by two peaks at 214 and $284 \mathrm{~nm}$. The latter is attributed to the low energy $n-p^{*}$ transition of the dinitramide ion (DN-), while the former is due to a high energy s-s* transition $[34,35]$. The present study obtained the same results for ADN/DMSO solutions. Figure 4 demonstrates temporal variations in the absorbance at $284 \mathrm{~nm}$ at various voltages. An applied voltage of $-1.5 \mathrm{~V}$, which corresponded to $E_{\mathrm{p} 3} \mathrm{c}$, was found to decrease the absorbance value, suggesting that the ADN was reduced and so decomposed above a specific voltage. Unfortunately, this study was not able to identify absorbance peaks associated with electrolysis products, and so further studies to identify such compounds in the liquid and gas phase will be required.

The present results suggest that ADN can undergo electrolysis in a solvent for which the potential window is sufficiently wide given the application of the appropriate voltage. As such, the electrolytic ignition of EILPs could be possible. The development of such systems will require additional data concerning the electrochemical properties of EILPs and the optimal electrolysis conditions (including the solvent, electrode, additives and catalyst).

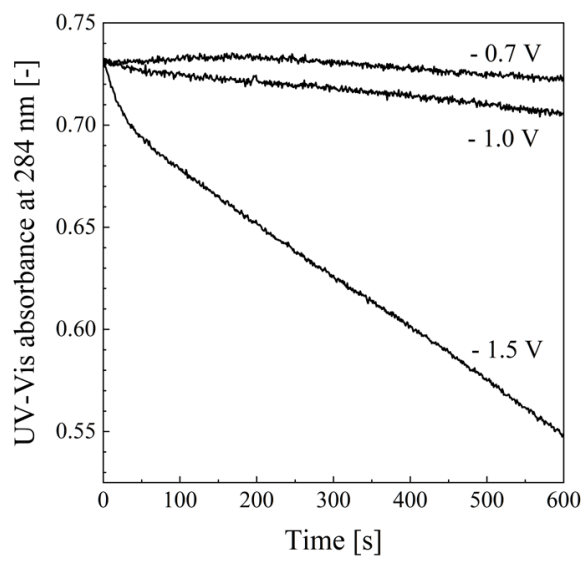

Figure 4. Temporal variations in the absorbance at $284 \mathrm{~nm}$ during the electrochemical reduction of ADN in DMSO. 


\subsection{Possible electrolysis mechanisms based on quantum chemistry calculations}

Quantum chemical calculations are a powerful tool that can be used to ascertain the reactions that should be excluded from a reaction mechanism based on thermodynamic arguments. Specifically, if a possible pathway is found to be highly endothermic, or considerably more endothermic than competing ones, then that reaction can be safely omitted from consideration. Before discussing reactions, it is helpful to examine the initial equilibrium state of ADN in solution. Under these conditions, ADN dissociates to form either an ionic pair ( $\mathrm{DN}^{-}$and $\mathrm{NH}_{4}{ }^{+}$) or an acidbase pair ( $\mathrm{HDN}$ and $\left.\mathrm{NH}_{3}\right)$. Our previous work $[36,37]$ using a computational approach established that dissociated $\mathrm{DN}^{-}$and $\mathrm{NH}_{4}{ }^{+}$are the most thermally preferred of all potential species in a high permittivity solution. Specifically, the Van der Waals complex formed by ADN, which is a complex between undissociated $\mathrm{DN}^{-}$and $\mathrm{NH}_{4}{ }^{+}$molecules, has a low Gibbs free energy similar to that of $\mathrm{DN}^{-}$, while the acid-base pair exhibits a higher Gibbs energy, and so is not preferred. Thus, both undissociated $A D N$ and $\mathrm{DN}^{-}$(in addition to $\mathrm{NH}_{4}^{+}$) will be the primary species in DMSO solutions, which is a polar solvent. Previous studies have also showed that liquid $\mathrm{ADN}$ has two isomers $\left(A D N_{I}=\mathrm{NH}_{4}-\mathrm{N}\left(\mathrm{NO}_{2}\right)_{2}\right.$ and $\left.A D N_{I I}=\mathrm{NH}_{4}-\mathrm{ON}(\mathrm{O}) \mathrm{NNO}_{2}\right)$ and it should be noted that the present study only considered $A D N_{\text {III }}$ because $\mathrm{NO}_{2}$. dissociation from $A D N_{\Perp}$ is preferable to that from $A D N_{1}$ [36].

The Gibbs energy profile for the reductive decomposition of $\mathrm{DN}^{-}$at the CBS-QB3// $\omega \mathrm{B} 97 \mathrm{X}-\mathrm{D} / 6-$ $311++G(d, p) / S C R F=(S M D$, solvent $=d m s o)$ level of theory is shown in Figure 5. The thermal decomposition of $\mathrm{DN}^{-}$, which proceeds via cleavage of the $\mathrm{N}-\mathrm{NO}_{2}$ bond $\left(\mathrm{DN}^{-} \rightleftarrows \mathrm{NNO}_{2}{ }^{-}+\mathrm{NO}_{2}\right.$ ) has an energy barrier of $127.8 \mathrm{~kJ} \mathrm{~mol}^{-1}$. In the case that a molecule is excited from the ground state, the Franck-Condon principle states that the structure and motions of the molecule are preserved but the electronic state and energy are different in the excited molecule (designated herein with an asterisk) after it relaxes to a stable structure in its new electronic state. In Figure 5, the $\mathrm{DN}^{-}$is both excited and reduced to the vertically excited state $\mathrm{DN}^{2-*}$, after which this species relaxes to $\mathrm{DN}^{2-}$ with the release of heat. The TS associated with the cleavage of the $\mathrm{N}-\mathrm{NO}_{2}$ bond in $\mathrm{DN}^{2-}$ was identified, and $\mathrm{NNO}_{2}^{-}$and $\mathrm{NO}_{2}^{-}$were determined to be the most likely products from the decomposition. The Gibbs energy barrier for this process was found to be $36.1 \mathrm{~J}$ $\mathrm{mol}^{-1}$, and the results further show that the excited $\mathrm{DN}^{2-*}$ may decompose through $\mathrm{DN}^{2-}$ and the TS to form $\mathrm{NNO}_{2}{ }^{-}$and $\mathrm{NO}_{2}{ }^{-}$. The associated energy barrier is much less than that for pyrolysis, indicating that electrolysis will proceed rather than pyrolysis.

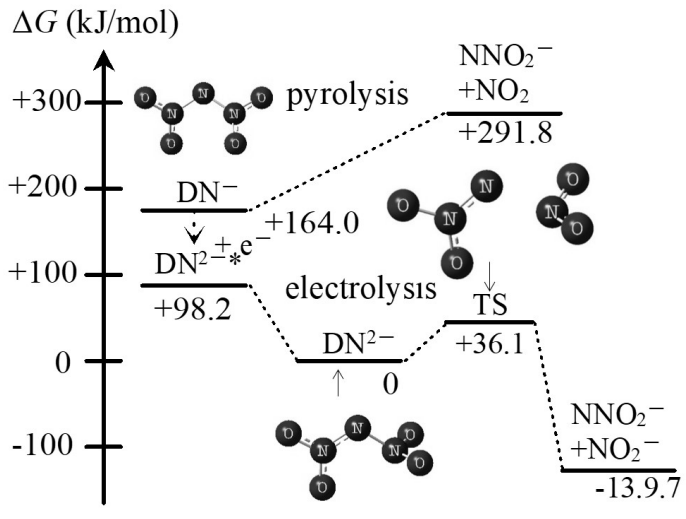

Figure 5. The Gibbs energy profile at $298.15 \mathrm{~K}$ for the reductive decomposition of $\mathrm{DN}^{-}$in $\mathrm{DMSO}$ solution as calculated at the CBS-QB3// $\omega$ B97X-D/6-311++G(d,p) level of theory.

The Gibbs energy profile for the reductive decomposition of ammonium dinitramide $\left(A D N_{I I}\right)$ is provided in Figure 6. This work identified a TS structure involved in the cleavage of the $\mathrm{N}-\mathrm{NO}_{2}$ bond in this species, and found that $\mathrm{NH}_{3}, \mathrm{~N}_{2} \mathrm{O}, \mathrm{NO}_{2}$ and $\mathrm{OH}^{-}$ are the most likely products from this decomposition. The CBS-QB3// $\omega B 97 X-D / 6-311++G(d, p) / S C R F=(S M D$, solvent $=\mathrm{dmso}$ ) calculations demonstrated that the associated Gibbs energy barrier was almost $0 \mathrm{~kJ} \mathrm{~mol}^{-1}$, and so the excited $A D N_{I^{-}}$would be expected to rapidly decompose. In contrast, the thermal decomposition based on the cleavage of the $\mathrm{N}-\mathrm{NO}_{2}$ bond (ADN $\| \rightleftarrows$ $\mathrm{NH}_{4} \mathrm{NNO}_{2}{ }^{-}+\mathrm{NO}_{2}$ ) has an energy barrier of $109.7 \mathrm{~kJ}$ $\mathrm{mol}^{-1}$, showing that electrolysis will proceed preferentially. Because the decomposition of $\mathrm{ADN}_{\mathrm{II}^{-}}$is thermally preferred to that of $\mathrm{DN}^{2-}$ (Figure 5), it is evident that this mechanism plays an important role in the irreversible decomposition observed during the $\mathrm{CV}$ analyses.

Interestingly, one potential product from ADN electrolysis is $\mathrm{NO}_{2} . \mathrm{NO}_{2}$ is also known to be the initial product generated during pyrolysis, which begins with the cleavage of the $\mathrm{N}-\mathrm{NO}_{2}$ bond in ADN $[36,37,38$, 39]. It is thus desirable for ADN-based propellants to have formulations that are highly reactive with $\mathrm{NO}_{2}$ in the condensed phase, and fuels having a low hydrogen abstraction energy have been shown to increase the pyrolytic reactivity of ADN [40]. It is likely that this same effect would appear during the electrolysis of ADN-based EILPs based on these computational results, meaning that electrolysis would generate $\mathrm{NO}_{2}$ from $\mathrm{ADN}$ and the $\mathrm{NO}_{2}$ would then react with the fuel. Although further comprehensive studies are needed, these preliminary data suggest that ADNbased EILPs could represent suitable propellants exhibiting a high degree of reactivity with $\mathrm{NO}_{2}$ and thus having the potential to ignite promptly in response to an electric current. 


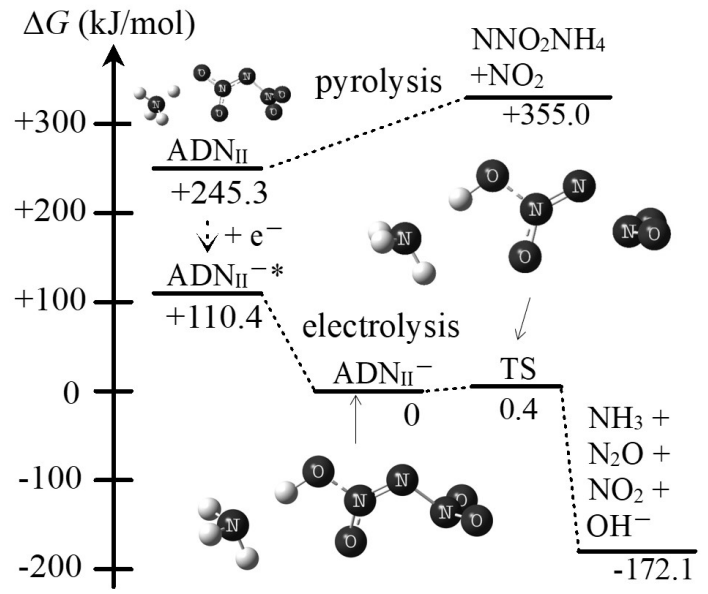

Figure 6. The Gibbs energy profile at $298.15 \mathrm{~K}$ for the reductive decomposition of $A D N_{\text {II }}$ in $\mathrm{DMSO}$ solution as calculated at the CBS-QB3// $\omega$ B97X-D/6-311++G(d,p) level of theory.

\section{Conclusions}

The eventual aim of our group is to develop ADNbased IL monopropellants together with a novel combustor using an electrolytic ignition system. As the first step, this work investigated the fundamental electrolysis properties of ADN in DMSO solution and also examined electrolysis mechanisms via quantum chemical calculations. The following conclusions can be drawn.

1) CV data acquired from ADN/DMSO solutions showed that ADN generates three redox peaks at $-0.69,-1.16$ and $-1.52 \mathrm{~V}$ together with two oxidation peaks at 0.34 and $0.50 \mathrm{~V}(\mathrm{vs} \mathrm{Ag} / \mathrm{AgCl})$ at a scan rate of $50 \mathrm{mV} \mathrm{s}^{-1}$.

2) UV-vis spectroelectrochemical trials established that an applied voltage of $-1.5 \mathrm{~V}$ decomposes ADN in DMSO solution, based on decreased UV-vis peak intensities. This result suggests that ADN can undergo electrolysis in specific solvents having suitably wide potential windows, and that this technique could be used to ignite EILPs.

3) Quantum chemistry calculations elucidated possible electrolysis mechanisms for ADN in DMSO, in which reduced $A D N_{1}-$ rapidly decomposes to form $\mathrm{NH}_{3}$, $\mathrm{N}_{2} \mathrm{O}, \mathrm{NO}_{2}$ and $\mathrm{OH}^{-}$. The associated Gibbs energy barrier is almost zero $\mathrm{kJ} \mathrm{mol}^{-1}$, as calculated at the

\footnotetext{
[a] Y. Izato, K. Matsushita Graduate School of Environment and Information Sciences

Yokohama National University

79-5, Tokiwadai, Hodogaya-ku, Yokohama,

Kanagawa, 240-8501, Japan

E-mail: izato-yuichiro-tk@ynu.ac.jp

[b] K. Shiota, A. Miyake Institute of Advanced Sciences Yokohama National University 79-5, Tokiwadai, Hodogaya-ku, Yokohama, Kanagawa, 240-8501, Japan

Supporting information for this article is available on the WWW under http://www.pep.wiley-vch.de .
}

CBS-QB3// $\omega$ B97X-D/6-311++G(d,p)/SCRF=(SMD, solvent $=$ dmso) level of theory. However, a more detailed understanding of the reactions that occur during the electrolysis of EILPs will be required in future.

\section{Acknowledgements}

This research was supported by the Foundation for the Promotion of Industrial Explosives Technology 2018 and JSPS KAKENHI Grant Number $17 \mathrm{H} 00844$.

\section{References}

[1] R. P. Singh, R. D. Verma, D. T. Meshri, and J. M. Shreeve, Energetic Nitrogen-Rich Salts and Ionic Liquids, Angew. Chem. Int. Ed., 2006, 45, 35843601. doi: 10.1002/anie.200504236.

[2] Q. Zhang, J. M. Shreeve, Energetic Ionic Liquids as Explosives and Propellant Fuels: A New Journey of Ionic Liquid Chemistry, Chem. Rev., 2014, 114, 10527-10574. doi: 10.1021/cr500364t

[3] Q. Zhang, J. M. Shreeve, Ionic Liquid Propellants: Future Fuels for Space Propulsion, Chem. Eur. J., 2013, 19, 15446-15451. doi: 10.1002/chem.201303131.

[4] I. V. Kuchurov, M. N. Zharkov, L. L. Fershtat, N. N. Makhova, S. G. Zlotin, Prospective Symbiosis of Green Chemistry and Energetic Materials, Chem. Sus. Chem., 2017, 10, 3914-3946. doi: $10.1002 /$ cssc. 201701053.

[5] S.V. Khomik, S.V. Usachev, S.P. Medvedev, A.A. Cherepanov, S.V. Stovbun, V.N. Mikhalkin, G.L. Agafonov, Ignition Characteristics of Hypergolic Fuels with Various N-Substituents, Proc. Combustion Institute, 2019, 37, 3311-3317. doi: 10.1016/j.proci.2018.05.144.

[6] S. Schneider,T. Hawkins, M. Rosander, G. Vaghjiani, S. Chambreau, G. Drake, Ionic Liquids as Hypergolic Fuels, Energy Fuels, 2008, 22, 2871-2872. doi: 10.1021/ef800286b.

[7] W. Zhang, X. Qi, S. Huang, J. Li, C. Tang, J. Li, Q. Zhang, Bis(borano)hypophosphite-Based lonic Liquids as Ultrafast-Igniting Hypergolic Fuels, J. Mater. Chem. A, 2016, 4, 8978-8982. doi: 10.1039/C6TA02699K.

[8] V.Stovbun, A.N.Shchegolikhin, S. V. Usachev, S. V. Khomik, S. P. Medvedev, Synthesis and Testing of Hypergolic Ionic Liquids for Chemical Propulsion, Acta Astronautica, 2017, 135, 110113. doi: 10.1016/j.actaastro.2016.11.047.

[9] T. Liu, X. Qi, B. Wang, Y. Jin, C. Yan, Y. Wang, Q. Zhang, Rational Design and Facile Synthesis of Boranophosphate Ionic Liquids as Hypergolic 
Rocket Fuels, Chem. Eur. J., 2018, 24, 1020110207. doi: 10.1002/chem.201801593.

[10] J. Li. X. Weng, C. Tang, Q. Zhang, W. Fan, Z. Huang, The Ignition Process Measurements and Performance Evaluations for Hypergolic Ionic Liquid Fuels: [EMIm][DCA] and [BMIm][DCA], Fuel, 2018, 215, 612-618. doi: 10.1016/j.fuel.2017.10.091.

[11] D. A. Newsome, G. L. Vaghjiani, D. Sengupta, An ab initio Based Structure Property Relationship for Prediction of Ignition Delay of Hypergolic lonic Liquids, Propellants Explos. Pyrotech., 2015, 40, 759-764. doi: 10.1002/prep.201400284.

[12] D. Sengupta, G. L. Vaghjiani, Molecular Orbital Based Design Guideline for Hypergolic Ionic Liquids, Propellants Explos. Pyrotech., 2015, 40, 144-149. doi: 10.1002/prep.201400087.

[13] A. E. Thomas, S. D. Chambreau, N. D. Redeker, A. A. Esparza, E. Shafirovich, T. Ribbeck, J. A. P. Sprenger, M. Finze, G. L. Vaghjiani, Thermal Decomposition and Hypergolic Reaction of a Dicyanoborohydride lonic Liquid, J. Phys. Chem. A, 2020 DOI: 10.1021/acs.jpca.9b09242.

[14] R. Fareghi-Alamdari, N. Zohari, N. Sheibani, Reliable Evaluation of Ignition Delay Time of Imidazolium lonic Liquids as Green Hypergolic Propellants by a Novel Theoretical Approach, Propellants Explos. Pyrotech., 2019, 44, 11471153. doi: $10.1002 /$ prep. 201800343.

[15] A. Larsson, N. Wingborg, Green Propellants Based on Ammonium Dinitramide (ADN), in: Advances in Spacecraft Technologies (Eds.: J. Hall), IntechOpen, London 2011. pp. 139.

[16] M. Y. Nagamachi, J. I. Oliveira, A. M. Kawamoto, R. C. L. Dutra, ADN- The New Oxidizer Around The Corner for An Environmentally Friendly Smokeless Propellant. J. Aerosp. Technol. Manage., 2009, 1, 153-160. doi: 10.5028/jatm.2009.0102153160.

[17] H. Östmark, U. Bemm, A. Langlet, R. Sanden, N. Wingborg, The Properties of Ammonium Dinitramide (ADN): Part 1, Basic Properties and Spectroscopic Data, J. Energ. Mater., 2000, 18, 123-138. doi: 10.1080/07370650008216116.

[18] M. Negri, M. Wilhelm, C. Hendrich, N. Wingborg, L. Gediminas, L. Adelöw, C. Maleix, P. Chabernaud, R. Brahmi, R. Beauchet, Y. Batonneau, C. Kappenstein, R-J. Koopmans, S. Schuh, T. Bartok, C. Scharlemann, U. Gotzig, M. Schwentenwein, New Technologies for Ammonium Dinitramide Based Monopropellant Thrusters - The Project RHEFORM, Acta.
Astronaut., 2018, 143, 105-117. doi: 10.1016/j.actaastro.2017.11.016.

[19] A. B. Fukuchi, S. Nagase, H. Maruizumi, M. Ayabe, HAN/HN-Based Monopropellant Thrusters, IHI Engineering Review, 2010, 43, 22-28.

[20] T. Katsumi, H. Kodama, T. Matsuo, H. Ogawa, N. Tsuboi, K. Hori, Combustion Characteristics of a Hydroxylammonium Nitrate Based Liquid Propellant. Combustion Mechanism and Application to Thrusters, Combust., Explos. Shock Waves, 2009, 45, 109-120. doi: 10.1007/s10573009-0055-z.

[21] B. N. Kondrikov, V. Annikov, Y. Egorshev, L. T. Luca, Burning of Hydroxylammonium Nitrate, Combust., Explos. Shock Waves, 2000, 36, 135145. doi: 10.1007/BF02701522.

[22] T. Katsumi, H. Kodama, H. Ogawa, N. Tsuboi, K. Hori, Combustion characteristics of HAN-based Liquid propellant, Sci. Technol. Energ. Mater, 2009, 70, 27-32.

[23] T. Katsumi, T. Inoue, J. Nakatsuka, K. Hasegawa, K. Kobayashi, S. Sawai, K. Hori, HANBased Green Propellant, Application, and Its Combustion Mechanism, Combust., Explos. Shock Waves, 2012, 48, 536-543. doi: 10.1134/S001050821205005X.

[24] T. W. Hawkins, A. J. Brand, M. B. McKay, M. Tinnirello, Reduced Toxicity, High Performance Monopropellant at the U.S. Air Force Research Laboratory, the 4th International Association for the Advancement of Space Safety Conference, May 19-21, 2020, Huntsville, USA

[25] K. Shiota, M. Itakura, Y. Izato, H. Matsunaga, H. Habu, A. Miyake A. Effects of Amide Compounds and Nitrate Salts on The Melting Point Depression of Ammonium Dinitramide. Sci. Technol. Energ. Mater., 2018, 79, 137-141.

[26] Y. Izato, K. Shiota, K. Satoh, T. Satoh, Y. Yahata, H. Habu, A. Miyake, Thermal and Evolved Gas Analyses of Decomposition of Ammonium Dinitramide-Based lonic Liquid Propellant Using TG-DSC-HRTOFMS. J. Therm. Anal. Calorim., 2019, 138, 1853-1861. doi: 10.1007/s10973-01908475-3.

[27] M. Najafi S. Darabi, Electrochemical Behavior and Voltammetric Determination of Ammonium Dinitramide Using a Graphene Film Modified Glassycarbon Electrode, Electrochim. Acta, 2014, 121, 315-320. doi: 10.1016/j.electacta.2013.12.145.

[28] M. J. Frisch, G. W. Trucks, H. B. Schlegel, G. E. Scuseria, M. A. Robb, J. R. Cheeseman, G. Scalmani, V. Barone, G. A. Petersson, H. 
Nakatsuji, X. Li, M. Caricato, A. V. Marenich, J. Bloino, B. G. Janesko, R. Gomperts, B. Mennucci, H. P. Hratchian, J. V. Ortiz, A. F. Izmaylov, J. L. Sonnenberg, D. Williams-Young, F. Ding, F. Lipparini, F. Egidi, J. Goings, B. Peng, A. Petrone, T. Henderson, D. Ranasinghe, V. G. Zakrzewski, J. Gao, N. Rega, G. Zheng, W. Liang, M. Hada, M. Ehara, K. Toyota, R. Fukuda, J. Hasegawa, M. Ishida, T. Nakajima, Y. Honda, O. Kitao, H. Nakai, T. Vreven, K. Throssell, J. A. Montgomery, Jr., J. E. Peralta, F. Ogliaro, M. J. Bearpark, J. J. Heyd, E. N. Brothers, K. N. Kudin, V. N. Staroverov, T. A. Keith, R. Kobayashi, J. Normand, K.

Raghavachari, A. P. Rendell, J. C. Burant, S. S. lyengar, J. Tomasi, M. Cossi, J. M. Millam, M. Klene, C. Adamo, R. Cammi, J. W. Ochterski, R. L. Martin, K. Morokuma, O. Farkas, J. B. Foresman, and D. J. Fox, GAUSSIAN 16, Revision B.01, Gaussian, Inc., Wallingford, CT, USA 2016.

[29] J. D. Chai, M. Head-Gordon, Long-Range Corrected Hybrid Density Functionals with Damped Atom-Atom Dispersion Corrections, Phys. Chem. Chem. Phys., 2008, 10, 6615-6620. doi: 10.1039/B810189B.

[30] J. A. Montgomery, M. J. Frisch, J. W. Ochterski, G. A. Petersson, A Complete Basis Set Model Chemistry. VI. Use of Density Functional Geometries and Frequencies, J. Chem. Phys., 1999, 110, 2822. doi: 10.1063/1.477924.

[31] A. Matsugi, H. Shiina, Kinetics of Hydrogen Abstraction Reactions from Fluoromethanes and Fluoroethanes, Bull. Chem. Soc. Jpn., 2014, 87, 890-901. Doi: 10.1246/bcsj.20140101.

[32] I. M. Alecu, J. Zheng, Y. Zhao, and D. G. Truhlar, Computational Thermochemistry: Scale Factor Databases and Scale Factors for Vibrational Frequencies Obtained from Electronic Model Chemistries, J. Chem. Theory Comput., 2010, 6, 2872-2887. doi: 10.1021/ct100326h.

[33] A. V. Marenich, J. C. Cramer, and D. G. Truhlar, Universal Solvation Model Based on Solute Electron Density and on a Continuum Model of the Solvent Defined by the Bulk Dielectric Constant and Atomic Surface Tensions, J. Phys. Chem. B, 2009, 113, 6378-6396. doi: 10.1021/jp810292n.

[34] N. G. Hossein, M. Ramin, F. Mohammad, K. Parviz, Synthesis of Ammonium Dinitramide by Nitration of Potassium and Ammonium Sulfamate. The Effect of Sulfamate Conterion on ADN Purity. Iran. J. Chem. Chem. Eng., 2008, 27, 85 -89.

[35] R. Gilardi, J. Flippen-Anderson, C. George, R. J. Butcher, A New Class of Flexible Energetic Salts: The Crystal Structures of the Ammonium, Lithium, Potassium, and Cesium Salts of Dinitramide, J.
Am. Chem. Soc., 1997, 119, 9411-9416. doi: 10.1021/ja9709280.

[36] Y. Izato, A. Miyake, The Decomposition Pathways of Ammonium Dinitramide on The Basis of Ab Initio Calculations, J. Energ. Mater., 2018, 36, 302-315. doi: 10.1080/07370652.2017.1405099.

[37] Y. Izato, A. Miyake, Detailed Kinetic Model for Ammonium Dinitramide Decomposition, Combust. Flame, 2018, 198, 222-229. doi: 10.1016/j.combustflame.2018.09.013.

[38] R. Yang, P. Thakre, V. Yang, Thermal Decomposition and Combustion of Ammonium Dinitramide (Review), Combust Explos Shock., 2005, 41, 657-679. doi: 10.1007/s10573-0050079-y.

[39] N. E. Ermolin, V. M. Fomin, On The Mechanism of Thermal Decomposition of Ammonium Dinitramide (Review), Combust. Explos. Shock Waves, 2016, 52, 556-586. doi: $10.1134 / \mathrm{S} 0010508216050087$.

[40] K. Shiota, Y. Izato, H. Habu, A. Miyake, Reactivity Analysis of Ammonium Dinitramide Binary Mixtures Based on Ab Initio Calculations and Thermal Analysis, J. Them. Anal. Calorim., 2019, 138, 2615-2622. doi: 10.1007/s10973-01908557-2.

Received: ((will be filled in by the editorial staff)) Revised: ((will be filled in by the editorial staff)) 
Full Paper

C. Author, B. Coauthor 